\title{
An analytical framework for managing container terminals
}

\author{
Y.H. Venus Lun* \\ Department of Logistics and Maritime Studies, \\ The Hong Kong Polytechnic University, \\ 11 Yuk Choi Road, Hung Hom, Kowloon, Hong Kong \\ E-mail: Venus.Lun@inet.polyu.edu.hk \\ *Corresponding author

\section{Pierre Cariou} \\ World Maritime University, \\ Citadellsvägen 29, P.O. Box 500, \\ S-201 24 Malmö, Sweden \\ E-mail: pierre.cariou@wmu.se
}

\begin{abstract}
This study aims to empirically develop a reference for terminal operators to evaluate their operational performance. This paper starts with a discussion on container terminal operations and the development of global container terminal operators. In this study, we applied data envelopment analysis (DEA) as a quantitative analytical tool to measure and evaluate the efficiency of global container terminal operators. In addition, we used regression modelling as a tool to formulate two regression equations as a reference for performance evaluation by container terminal operators. Our findings indicate that efficient global terminal operators are global stevedores. Accordingly, we propose a 'PROFIT' framework, which consists of the dimensions of productivity, regional coverage, operating efficiency, focus of business, internationalisation and terminal network, which is useful for a container terminal to manage their terminal operations and development.
\end{abstract}

Keywords: container terminal; terminal operations; terminal performance.

Reference to this paper should be made as follows: Lun, Y.H.V. and Cariou, P. (2009) 'An analytical framework for managing container terminals', Int. J. Shipping and Transport Logistics, Vol. 1, No. 4, pp.419-436.

Biographical notes: Venus Lun is a Lecturer at The Hong Kong Polytechnic University. Her research interests include shipping logistics, port economics, container transport operations and liner shipping management. She is the author of a number of books on shipping and logistics, including Container Transport Management, Adoption of Electronic Commerce by Logistics Service Providers and Shipping and Transport Logistics. Her research papers have been published in such scholarly journals as International Journal of Production Economics, International Journal of Shipping and Transport Logistics, Transport Reviews and Transportation Journal. She has worked in the liner shipping industry for over ten years, occupying managerial positions in top shipping firms such as Maersk, Hapag-Lloyd and CMA CGM. 
Pierre Cariou is a Professor at the World Maritime University (WMU) in Malmö, Sweden. He is holding the French Chair in Maritime Affairs and he is in charge of Shipping and Port Management specialisations since September 2006. He received his $\mathrm{PhD}$ in Applied Economics in 2001 from the University of Nantes (France). His current research focuses on liner shipping markets, maritime safety and port economics.

\section{Introduction}

Ports are places where there are facilities for berthing ships, and where there are handling quay cranes to handle cargo transfer from ships to shores, shores to ships, or ships to ships. According to Robinson (2002), ports serve as:

- places that handle ships and cargoes

- operating systems that handle ships and cargoes with operational efficiency

- economic units that handle ships and cargoes within an economic efficiency framework

- administrative units that handle ships and cargoes within an administrative unit and policy framework.

Being a vital part of the transport infrastructure, ports are nodes that link with other inland transport modes such as highways, railways, and inland waterway systems (Lun et al., 2008). Ports not only act as gateways for trade, but also attract industrial activities and agents of commercial infrastructure, e.g., financial institutions and insurance agents. This has resulted in a tendency towards logistics integration in the port (Notteboom and Winkelmans, 2001; Heaver et al., 2000). Ports have evolved from a cargo handling point to a distribution centre with physical infrastructure serving as transport hubs in the container supply chains. Hence, it becomes an interface between the areas of production and consumption, attracting the attention of market players in the shipping and logistics related business.

Moreover, ports link the key players of the container community, such as container terminal operators and shipping lines, in the international container logistics chain (Lun et al., 2009). Container terminal operators control the activities from receiving containers to loading onto ships and from dispatching containers to discharging from ships. Container terminal operators also undertake activities such as yard planning, quayside planning, and vessel stowing planning. On the other hand, shipping lines operate containerships and provide liner shipping services to shippers. Shipping lines offer shippers door-to-door services and integrated logistics services by coordinating with feeder operators, road carriers, rail operators, logistic service providers, and terminal operators.

The development of global operations has put pressure on the provision of liner shipping services and the extension to land-side operations (Carbone and Martino, 2003). Since the sailing of Ideal-X in April 1956 from Newark to Houston, containerisation has changed ship routing, ship design, ship size, handling facilities, port management, inland transport operations, commercial practices and information systems. To handle 
containers, ports have to invest in specialised equipment to offer container handling services to shipping lines (Bichou et al., 2007). To operate effectively and efficiently, sea-side and land-side operational activities must be well-coordinated, since such activities as transfers of containers from intermodal yard to container terminal and loading/unloading of containers to/from ships are closely interrelated and interdependent. To improve operational efficiency, container terminal operators have invested in state-of-the-art information systems to link up sea-side and land-side activities within an integrated system. Over the past few decades, technological developments have considerably altered the organisational relationships within the port community.

Martin and Thomas (2001) identified the interorganisational relationships of players in the container transport chain as follows:

- Shipping line - inland transport operator: The relationship between shipping line and road haulage has become closer. To work with road operators closely, shipping lines often nominate a limited number of truckers to handle their road transport. From the perspective of intermodal transport development, liner-oriented intermodalism has emerged as an extension of liner shipping with liner operators controlling the cargo and rail operators, and coordinating their services with scheduled ship arrival times.

- Terminal operator -shipping line: The recent development of network-based management has contributed to the development of closer relationships between terminal operators and shipping lines. However, from the perspective of terminal operators, the purchase of terminal services is confined to a few large ocean carriers, resulting in shipping lines wielding high bargaining power. Such phenomenon is found to influence the operations of all types of ports including feeder ports, hub ports and direct call ports.

- Shipping line - freight forwarder: As shipping lines may be in a conflicting position when they recommend shipping services to their shippers, many shippers prefer an independent freight forwarder. As a result, shipping lines need to treat freight forwarders as their customers and continue to be dependent on freight forwarders and their relationships with shippers for continued growth.

While the container shipping industry faces constantly changing technologies, processes and organisational structure, it is important that managers of container terminals are able to manage these challenges (Barber, 2008). Although international container shipping operations plays an important role in global economic development, relatively few studies have been devoted to the container terminal. While empirical study on operational efficiency of container terminals is lacking, this study adds to the literature by achieving the following objectives:

1 To identify the efficient container terminal operators by comparing the operating cost per TEU.

2 To understand the relationship between terminal throughput and operating cost, we conduct a regression analysis and formulate a regression equation to examine how the operating cost influences the terminal throughput in the container terminal industry. 
3 To gain an understanding of the factors influencing operational efficiency, we use correlation analysis to test the relationship among the variables that affect the performance of container terminal operators.

4 To develop a quantitative forecasting tool to help forecast the profit of container terminal operators.

5 To evaluate and measure the performance of container terminal operators, the quantitative analytical tool data envelopment analysis (DEA) is used to identify efficient decision-making units (DMUs).

\section{Container terminal operations}

Vis and Koster (2003) suggested that the handling procedures at container terminals can be divided into several subprocesses. First, when a ship arrives at the port, inbound containers have to be discharged from the ship. This is handled by quay cranes, which take the containers out of the ship's hold (for under deck containers) or from the deck (for on deck containers). Next, the containers are transferred from quay cranes to vehicles that travel between the quayside to the stack at the container yard (CY). This stack consists of a number of blocks where containers can be stored. The CY is served by yard cranes (e.g., straddle carriers). A straddle carrier can transport containers and store them in a stack. It is also possible to use dedicated vehicles to transport containers and use stack cranes to discharge containers from the vehicles and store them in the stack. When containers are ready to be moved, they are retrieved from the stack by cranes for transport by vehicles to intermodal transport modes such as barges, trucks, or trains or to deep sea ships for transhipping to other ports. This process can also be executed in reverse order to load outbound containers on board a ship.

The main facilities in container terminals include quay, $\mathrm{CY}$, container freight station (CFS), interchange area, gate facility, railhead, and others (Lun et al., 2006):

- Quay: Quay is an essential facility where vessels berth to discharge and load containers. With the deployment of super post-Panamax ships, a length of about 250 to 350 metres with a depth of 15 to $16 \mathrm{~m}$ of water alongside can be considered about right to accommodate large container ships. There may be a ramp at one end of the quay for serving roll-on roll-off ships to allow vehicles to be driven directly on and off a ship and onto the quay side. Quay must be wide enough to accommodate large quay side gantry cranes that serve in most terminals for loading and discharging containers. It provides space for containers to be landed and for container-handling equipment to pick up and drop off containers. It also provides space for containers to be temporarily stacked at the back of the quay for restowing purposes.

- CY: CY typically takes up about $60 \%$ to $70 \%$ of the total terminal area. It is primarily used to stack containers waiting for onward movement. Containers are stored in well-marked and numbered blocks. Blocks are linked by roadways and aisle ways along which vehicles and equipment travel. Some blocks are reserved for export containers (normally near to the seaside of the yard) and some blocks are reserved for import containers. Another area is reserved for stacking empty containers. Since spaces within container terminals are usually limited, empty containers may be located in off-dock depots. Some stacking areas are set aside for 
special containers such as reefers, out of gauge (OOG) cargoes and dangerous cargoes.

- $\quad C F S$ : Not all container terminals have a CFS. Inbound containers are unpacked in the CFS and the separated consignments of cargo are stored awaiting collection. Outbound consignments are consolidated and packed into empty containers before moving to the CY for shipment. It consists of covered or open areas for storing cargoes. Some areas are set aside for various inspection functions such as customs examination of containers and their contents.

- Interchange area: Interchange area allows road vehicles to deliver and collect containers. There are two types of interchange areas. The first type of interchange is a separate area. Containers are brought to or taken from road vehicles parked at slots at the interchange by transfer equipment. The second type is a series of lanes running along one side of each storage space. Road vehicles are permitted to drive into the $\mathrm{CY}$ and to take and collect their containers at positions alongside the stacks where stacking equipment lifts and lands the containers.

- Gate facility: Movement of containers into and out of a terminal is controlled at a gate facility where documentation, security and inspection procedures are attended to. There is a series of lanes separated by cabins in which gate clerks and inspectors are based. It is usually equipped with a weight bridge and raised walkways to allow the inspection of container tops. Containers may be held at the gate due to either incomplete documentary formalities or congestion at the gate house. Parking areas may be provided for holding vehicles before allowing them to go into the CY.

- Railhead: For containers arriving or leaving by rail, an on-dock rail reception/dispatch railhead may be provided. The wagon may need to be shunted into appropriate loading and unloading sequences. It may have its own yard to store containers and trailers and its own gate facility. Inspection and administrative facilities are provided at the railhead.

- Others: This category includes administration building and maintenance workshop. The administration building consists of offices where staff members are engaged in planning, administrative and documentary activities. Terminal operations are usually coordinated and controlled from a control tower in the office building. Office accommodations are provided for customs, security and other support services. Maintenance workshop is the facility in a terminal that carries out regular maintenance and repair work on terminal equipment, and provides container repairing services for shipping lines.

To improve operational efficiency, container terminals invest in integrated systems such as enterprise-resource-planning (ERP). ERP is the enterprise-wide information system designed to coordinate all the resources, information and activities needed to complete the container handling processes. ERP is useful for managing a container terminal as it reduces time in information system development by providing standardised workflows and effective business planning capability.

Choi et al. (2003) presented an ERP approach to developing container terminal operating systems and suggested that a container terminal ERP system should comprise planning and operation modules, including berth planning, yard planning, 
loading/unloading planning, railway planning and resource allocation planning, to control overall terminal operations.

- Berth planning: Berth planning includes berth configuration, vessel information management (which covers general information about vessels such as service routes and navigation features), vessel arrival/departure schedule management and berth allocation (which covers allocation management of berths and container cranes). The system must be flexible in design to cope with frequent changes in vessel arrival/departure schedules.

- Yard planning: Yard planning includes yard configuration management, yard planning for export, import and transhipment containers, yard planning for empty containers, and relocation within the CY. Planning the yard allocation for export cargo involves considerations of vessel status and yard status. Yard allocation for import cargo is performed after unloading planning is completed.

- Loading/unloading planning: Loading/unloading planning consists of management of vessel data (which include detailed specifications of the vessel, structure of the cargo hold, draught, special data for the calculation of vessel stability and the strength of the structure), container crane planning, unloading planning and loading planning. Container crane planning identifies the cargo amount in each hatch by each port where the cargo will be unloaded and loaded, determines what container cranes are allocated for which vessels, the starting time of work and the status and location of each container crane.

- Railway planning: It includes rail yard and freight train configurations, arrival/departure control and loading and unloading planning for railway transport.

- Resource allocation planning: It includes resource analysis such as equipment allocation and manpower allocation.

- Overall control: It relates to vessel control, yard control and gate control. Terminal control sends work orders to workers of container cranes, yard tractors and yard cranes based on the details of the unloading and loading plan, as well as the equipment allocation plan.

- Terminal operations: It involves unloading and loading from and onto vessels, gate in and out yard management, as well as reefer container and dangerous goods container management.

\section{Development of global container terminal operators}

Increased ship size has led to the division of container ports into three segments, namely hub ports, feeder ports and direct-call ports (Geraldo et al., 2003). Under these diversified port service market segments, the balance of power has moved in favour of the shipping lines, which can exert pressure on ports to improve productivity and capacity (Martin and Thomas, 2001). The success of liner services in a hub-and-spoke system resulting from economies of scale achieved at sea should not be negated by diseconomies of scale in ports. Today, four or five cranes are standard in major ports for post-Panamax ships. 
Clearly, serving of large vessels efficiently incurs higher port costs due to excess port capacity and availability of cargo handling equipment.

Shipping lines consider container terminals as part of their international networks of transport and logistics services. The development in Rotterdam of Maersk dedicated terminal is an example. Maersk now has its own dedicated terminals, while the other members of the Grand Alliance have also been granted a dedicated container terminal (DCT), but the World Alliance has moved to ECT's Delta Dedicated West Terminal (Heaver et al., 2001). The market share of large multi-user terminal providers has gradually diminished. A shipping company with a long-term commitment to a dedicated terminal is less inclined to switch to alternative ports of call. Dedicated terminals provide opportunities for port authorities to push for more investment in ports. It is also a useful strategy if there is competition between different port terminal operators nearby. With the development of DCTs, the multi-user terminal operators face keen competition. For port authorities, dedicated terminals are a means to facilitate the development of integrated services and to bind shipping companies to the terminals. DCTs offer carriers greater flexibility, reliability, shorter turnaround times and enhanced efficiency in the management of global container movements (Cariou, 2008). The level and scope of accessibility to a DCT is determined by an agreement between carriers and port operators. The deals between shipping lines and terminal operators can involve the use of berths for other container terminal operations such as stacking areas, as well as inland connections. The choice of a terminal operator may affect the amount of interterminal competition in the port. With the shift of terminals to an integrated network-based transport system, the extent of transport system competition has increased. This suggests that competition among terminals can be expected to increase.

Ports need to consider competition from other nearby ports. For instance, the port of Hong Kong faces severe competition from regional ports such as Singapore and ports located in Southern China such as Yantian. Hong Kong's leading position for China outbound cargo is under competitive threat. On the other hand, port cooperation exists (e.g., cooperation exists between Hong Kong and Yantian because of Hutchison Port Holdings (HPH) Group's common share in the two container terminals). A similar situation exists between Hong Kong and Chiwan through MTL's common ownership. As a result of rapid integration between Hong Kong and South China, a structural transformation in container port operations has been found in the territory's economy. Hong Kong is handling a very large share of China's external trade. The China factor is undoubtedly a major driving force for the further development of the economic growth of Hong Kong. On the other hand, China is catching up fast as its port facilities are developing rapidly.

The restructuring of international shipping and logistics systems has put pressure on container terminal operators to provide high quality services at low cost (Notteboom, 2004). In response to competition, there are three patterns of development in the terminal industry: terminal network, regional coverage and internationalisation.

\section{Terminal networks}

Faced with mergers and alliances among shipping lines, development of global container terminal operators, and requirements for larger investment in terminal facilities, terminal operators are prompted to go down the path of networking with other operators. For 
example, HWL announced in June 2005 that it had agreed to sell $20 \%$ and $10 \%$ effective equity in HIT and COSCO-HIT, respectively, to PSA for a cash amount of US\$925 million (http://www.worldcargonews.com).

\section{Regional coverage}

To increase the intensity of container terminal operations in a region can be a strategy for terminal operators to serve markets more effectively and gain market power. This can be done by increasing the scope of services offered and providing similar services in adjacent locations. For example, multimodal transport services are provided at Yantian International Container Terminals (YICT). Its scope of services include: railway transport, warehousing services, and support services. Railway transport offers bulk and containerised transport and transhipment services. Warehousing services include cargo loading and unloading, storage, packing and labelling. Support services are container storage and maintenance, assistance in customs declaration and inspection, trucking and inland operations (Transportation Services at YICT). With a wide range of logistics services provided, the intensity of a terminal operator's operations in a region will be increased.

\section{Internationalisation}

Global expansion of container trade has encouraged the growth of specialised container terminal operations. The container terminal operators that have resources to invest in terminal facilities and equipment, possess rich experience in managing container terminals and have expertise in port and terminal technology are in a good position to extend their container terminal business internationally. An example of a global leader is HPH. HPH operates 247 berths in 42 ports, along with a clutch of transport-related service companies. In 2005, the HPH Group handled 51.8 million TEU (http://www.hph.com.hk).

Major container terminal operators are groups with specialisation and international expertise in container terminal management and development (Geraldo et al., 2003). The terminal throughputs of the top global container terminal operators are listed in Table 1. In general, global container terminal operators can be categorised as follows (Drewry, 2005):

- Global stevedores: These operators are companies whose primary business is port operations. These companies were pioneers of international port development such as HPH and PSA. Characteristics of global stevedores' terminal operations are

1 terminal operation is the primary focus of their business

2 terminals are run as profit centres

3 greater efficiency is gained by implementing common systems across the terminal network to improve productivity

4 extensive networks spread investment risk.

- Global carriers: These operators are companies whose main business is container shipping, but which have investments in container terminals as a vertical integration 
tool to support their core business. Examples are K Line and OOCL. Characteristics of global carriers' terminal operations are

1 container shipping is the prime business focus

2 terminals are often run as cost centres

3 greater efficiency is gained by integrating the terminal with the wider service network

4 extensive networks support shipping activities/strategy.

Table 1 Container throughputs of the top global container terminal operators

\begin{tabular}{lcc}
\hline Operator & Million TEU in 2006 & \% of total global throughput \\
\hline HPH & 60.9 & $13.80 \%$ \\
APMT & 52.0 & $11.80 \%$ \\
PSA & 47.4 & $10.10 \%$ \\
DPW & 41.6 & $9.40 \%$ \\
Cosco & 22.0 & $5.00 \%$ \\
Eurogate & 11.7 & $2.70 \%$ \\
Evergreen & 9.4 & $2.10 \%$ \\
MSC & 8.8 & $2.00 \%$ \\
SSA & 7.6 & $1.70 \%$ \\
HHLA & 6.6 & $1.50 \%$ \\
APL & 5.9 & $1.30 \%$ \\
Hanjin & 5.4 & $1.20 \%$ \\
OOCL & 4.8 & $1.10 \%$ \\
Dragados & 4.7 & $1.10 \%$ \\
CMACGM & 4.5 & $1.00 \%$ \\
NYK Line & 4.1 & $0.90 \%$ \\
MOL & 3.3 & $0.80 \%$ \\
K Line & 3.1 & $0.70 \%$ \\
Grup TCB & 2.9 & $0.60 \%$ \\
ICTSI & 2.2 & $0.50 \%$ \\
\hline
\end{tabular}

Source: Drewry (2007)

For global carriers, they face fluctuations of freight rates. To reduce slot costs, they need to deploy large ships to pursue economies of scale. Using mega containerships involves extra operational resources (Midoro et al., 2005). First, the loading and unloading of containers for mega ships increases port time. When increasing ship size from a 4,000 TEU Panamax to an 8,000 TEU super post-Panamax, the time the vessel spends in ports increases from $17 \%$ of overall voyage time to $24 \%$. This means that terminal operations play a critical role in schedule reliability when deploying mega ships. Besides, the use of mega ships increases transhipment operations. Large ships usually adopt the hub-and-spoke approach (Lun and Browne, 2009). In this way, transhipment activities in world throughput increased from $18.3 \%$ in 1990 to $27 \%$ in 2002 . In addition, the 
handling of mega ships increases stevedoring costs as mega ships require deeper water, longer berths and more quay cranes to load and unload containers. Higher requirements for facilities mean that few ports can handle mega ships. Higher charges for advanced container terminals with better facilities would increase shipping lines' production costs.

Container terminal operators encounter problems in managing equipment and facilities to handle mega ships during peak periods. Due to the operational difficulties generated in multi-user terminals and a limited number of terminals available to handle mega ships, the use of DCTs has witnessed an increase. The use of DCTs and the need for transhipment operations have led to an increase in terminal costs for shipping lines. Together with the inadequacy of terminal capacity in some congested areas, shipping lines are seeking to control a number of terminal facilities all over the world. Other drivers for shipping lines to acquire control over terminals are reduction in stevedoring costs and improvement in schedule reliability. Pioneer liners that have invested in container terminals are APMT. Examples of followers are K Line and OOCL.

\section{Research design}

The main objective of this study is to measure and evaluate the efficiency of global container terminal operators. It is desirable to use empirical data to evaluate firm performance (Cho et al., 2008). In this study, we evaluate the efficiency of global container terminal operators, data of terminal throughput, profit in terms of total earning and operating cost (i.e., the difference between total revenue and total earning) were collected from Drewry in 2007. Data of the sample container terminal operators is shown in Table 2.

Table 2 Data to evaluate the performance of container terminal operators

\begin{tabular}{lccc}
\hline Terminal operator & Terminal throughout & Terminal profit $* *$ & Operating cost $^{* *}$ \\
\hline Eurogate & 12.20 & 92.36 & 647.07 \\
HPH & 62.00 & 1456.00 & 2767.00 \\
ICTSI & 2.30 & 51.04 & 191.56 \\
K Line & 4.80 & 61.34 & 875.26 \\
OOCL & 4.80 & 80.30 & 419.70 \\
PSA & 51.29 & 965.60 & 1470.90 \\
APMT & 52.10 & 333.00 & 1732.00 \\
\hline
\end{tabular}

Notes: *in million TEU

$* *$ in million USD

This study uses several quantitative tools to examine the efficiency of global container terminal operators. To begin, we use a DEA approach to compare the operating cost per TEU of global container operators to identify the most cost efficiency DMUs. A DMU is regarded as the entity responsible for converting input into output and whose performance are to be evaluated. Other than cost efficiency, profit is also an important determinant to influence the DMU's performance. To provide an understanding on how terminal throughput and its cost are associated, we conduct a regression analysis to examine the relationship between the dependent and independent variables. We also 
formulate a regression equation to examine the relationship between operating cost of terminal throughput in the container terminal industry.

The second step of this study is to use correlation analysis to empirically test the relationship among the variables of operating cost, terminal profit and throughput to gain an understanding of the factors influencing operational efficiency in container terminals. Forecasting is necessary for DMUs to determine the future development. In container terminal operations, quantitative forecasting can be the starting point for effective decision-making. This study uses a regression analysis technique to develop a regression equation to predict the profit of DMUs. To examine the performance of container terminal operators, it is useful to identify the efficient DMUs. We, therefore, use the quantitative analytical tool DEA to identify the most efficient DMUs.

\section{Test results}

DEA is a quantitative analytical tool to measure and evaluate the efficiency of organisations under study (Boussofiane et al., 1991). Efficiency can be defined as the ratio of the output to the input of any system. In DEA, the organisation under study is called a DMU. In this study, we use DEA as one of the approaches to evaluate the efficiency of global container terminal operators. DEA has grown into a powerful analytical tool for measuring and evaluating performance (Cooper et al., 2007). In container terminal operations, performance measures in the form of a ratio can be defined simply as:

Efficiency score $=$ Output $/$ Input

To calculate the efficiency score, we use single output to single input case apply formula (1) to the following.

Table 3 Cost per TEU and efficiency score of DMUs

\begin{tabular}{lccccccc}
\hline DMU & Eurogate & HPH & ICTSI & K Line & OOCL & PSA & APMT \\
\hline Terminal throughput & 12.20 & 62.00 & 2.30 & 4.80 & 4.80 & 51.29 & 52.10 \\
Total operating cost & 647.07 & 2767.00 & 191.56 & 875.26 & 419.70 & 1470.90 & 1732.00 \\
Cost per TEU & 53.04 & 44.63 & 83.29 & 182.34 & 87.44 & 28.68 & 33.24 \\
Efficiency score & 0.54 & 0.64 & 0.34 & 0.16 & 0.38 & 1.00 & 0.86 \\
\hline
\end{tabular}

Table 3 shows the cost per TEU as a measure of cost efficiency in container terminal operations. By this measure, PSA is the DMU operating with the lowest cost per TEU. Then, we can measure the efficiency of others relative to PSA by

$$
0 \leq \text { Cost per TEU of PSA / Cost per TEU of other DMUs } \leq 1
$$

and arrange them in the following order by reference to the results shown in Figure 1

$$
1=\mathrm{PSA}>\mathrm{APMT}>\mathrm{HPH}>\text { Eurogate }>\text { ICTSI }>\text { OOCL }>\mathrm{K} \text { Line }=0.16
$$

This study not only measures the efficiency of container terminal operators but also examines the relationship between terminal throughput and its operating cost. To understand how the input affects outputs, we use linear regression analysis to examine the 
relationship between terminal throughout and operating cost. The results of regression analysis are shown in Table 4 . The results indicate that operating cost is a good indicator to predict terminal output with $R=0.923$ and the relationship is significant at the $p=0.003$ level. The value of 0.923 indicates that the terminal throughput can be well predicted by the operating cost of the terminal. The $R^{2}$ of 0.851 suggests that $85.1 \%$ of the observed variability is explained by the independent variable.

Figure 1 Efficiency of DMUs (on cost per TEU) (see online version for colours)

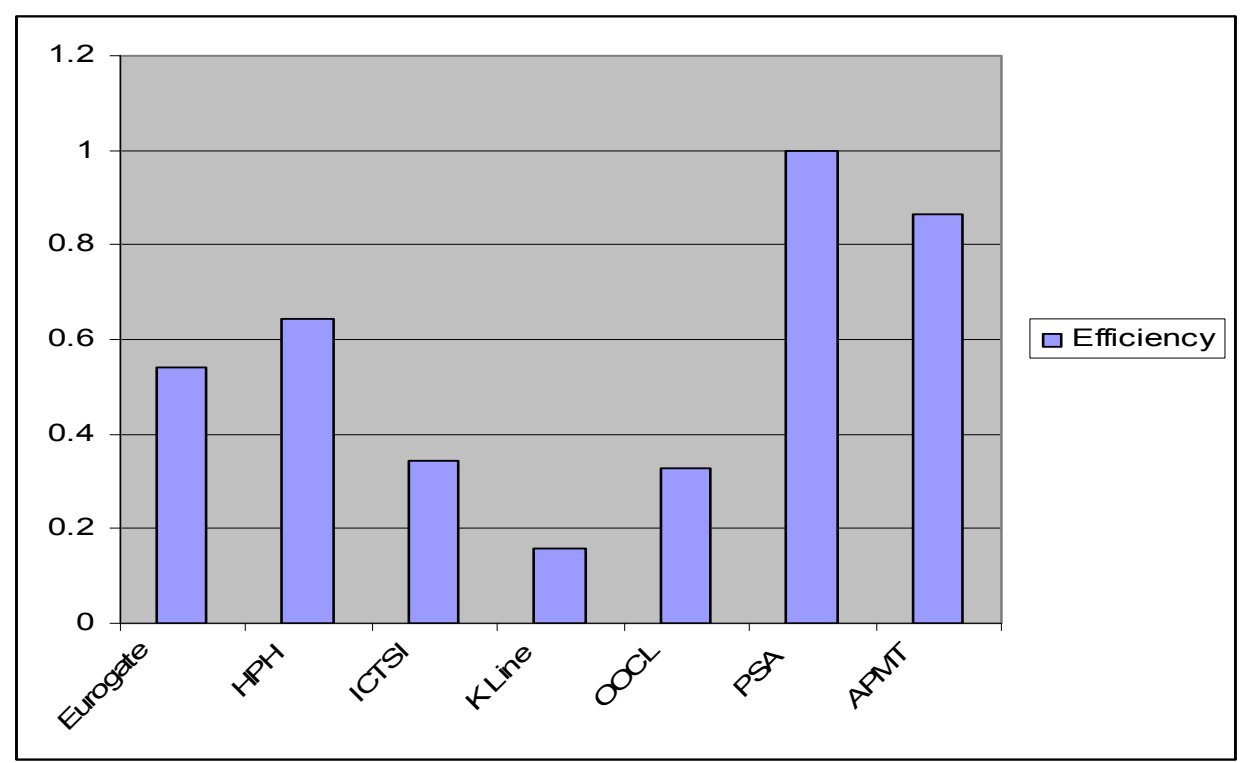

Table 4 Results of regression analysis to examine the relationship between total cost and terminal throughput

\begin{tabular}{lccccccc}
\hline Independent variable & Dependent variable & $R$ & $R^{2}$ & $d f$ & sig & Constant & $\beta$ \\
\hline Operating cost & Terminal throughput & 0.923 & 0.851 & 5 & 0.003 & -4.627 & 0.027 \\
\hline
\end{tabular}

To predict the terminal throughput, we use the regression analysis technique to develop an equation (Lun and Quaddus, 2009). The fitted regression equation is of the form

$$
Y=b_{0}+b_{1} X_{1}
$$

where

$b_{0} \quad$ intercept

$b_{1} X_{1} \quad$ linear effect of $\mathrm{X} 1$

The coefficients for the independent variable to affect terminal throughput are listed in column $\beta$ of Table 4 . Using these coefficients, the following regression equation to predict fleet size can be obtained:

$$
T T=-4.627+0.027 O C
$$


where

TT terminal throughput

$O C$ operating cost

In the regression equation (E1), the operating cost is the determinant of terminal throughput in the container terminal operations. The $\beta$ coefficient (i.e., 0.027) in the equation has a positive value meaning that the predicted value of terminal throughput increases when the operating cost increases.

Based on the calculation from formula (2), efficiency in terms of cost per TEU of the DMUs has been determined. Other than cost efficiency, profit is also a key factor for the DMUs to evaluate their performance. To understand how the terminal throughput, terminal profit and operating cost are associated, we conduct a correlation analysis to examine the direction, strength, and significance of the relationship of these variables. The results of correlation analysis are shown in Table 5. Our results suggest that there is a positive relationship between terminal throughput and operating cost with a correlation coefficient of 0.923 at a significance level of $p=0.003$. Our findings also suggest a positive relationship between terminal profit and operating cost with a correlation coefficient of 0.887 at a significance level of $p=0.008$. These results indicate that both of the outputs of terminal throughput and terminal profit are associated with the operating cost.

Table 5 Correlation relationship among the variables of terminal throughput, terminal profit and operating cost

\begin{tabular}{lcccc}
\hline & & $\begin{array}{c}\text { Terminal } \\
\text { throughput }\end{array}$ & $\begin{array}{c}\text { Terminal } \\
\text { profit }\end{array}$ & Operating cost \\
\hline Terminal & Pearson correlation & 1.000 & & \\
throughput & Sig. (2-tailed) & & & \\
Terminal profit & Pearson correlation & $0.862^{*}$ & 1.000 & \\
& Sig. (2-tailed) & 0.013 & & \multirow{2}{*}{1.000} \\
Operating cost & Pearson correlation & $0.923^{* *}$ & $0.887^{* *}$ & \\
& Sig. (2-tailed) & 0.003 & 0.008 & \\
\hline
\end{tabular}

Notes: *Correlation is significant at the 0.05 level (2-tailed)

**Correlation is significant at the 0.01 level (2-tailed)

In this study, we also use linear regression analysis to examine the relationship between terminal profit and its operating cost. The results of regression analysis are shown in Table 6 . The results indicate that operating cost is a good indicator to predict terminal performance with $R=0.887$ and the relationship is significant at the $p=0.008$ level. The value of 0.887 indicates that the linear regression model predicts well. The $R^{2}$ of 0.787 suggests that $78.7 \%$ of the observed variability of terminal profit is explained by the operating cost.

Table 6 Results of regression analysis to examine the relationship between operating cost and terminal profit

\begin{tabular}{lccccccc}
\hline Independent variable & Dependent variable & $R$ & $R^{2}$ & $d f$ & sig & Constant & $\beta$ \\
\hline Operating cost & Terminal profit & 0.887 & 0.787 & 5 & 0.008 & -203.411 & 0.551 \\
\hline
\end{tabular}


To predict the terminal profit, regression analysis technique is used to develop a regression equation. Using these results, the following regression equation to predict terminal profit can be obtained:

$$
T P=-203.411+0.551 O C
$$

where

$T P$ terminal profit

$O C$ operating cost

In the regression equation (E2), operating cost is the indicator of terminal profit in the container terminal operations. The $\beta$ coefficient (i.e., 0.551 ) in the equation has a positive value meaning that the predicted values of terminal profit increases when the operating cost increases.

The next step is to evaluate terminal operators in terms of the input of operating cost and output of both total terminal throughput and profit. To examine the efficiency in terms of a single input (i.e., operating cost) and two outputs (i.e., terminal throughput and profit), we use the CCR model which was initially proposed by Charnes, Cooper and Rodes in 1978. The CCR model considers constant returns to scale of activities (Zhou et al., 2008). To deal with multiple outputs, one way to simplify the calculation of efficiency score would be to weight the various outputs and inputs by weights. To evaluate DMU's efficiency, DEA uses variable weights to measure the input and output. In the CCR model, linear programming is used to determine the weight so as to maximise the ratio of output/input. The optimal weights generally vary from one DMU to another DMU. Thus, the weights in DEA are derived from the data instead of being fixed in advance. Each DMU is assigned a set of weights with values that may vary from one to another.

The CCR model consists of CCR input-orient (CCR-I) model and CCR output-orient (CCR-O) model. The CCR input-orient model aims to minimise the input while satisfying the output levels while the CCR output-orient model attempts to maximise outputs without requiring more input values. In this study, we use the DEA-Solver software to run the CCR-I model. The results are shown in Table 7.

Table 7 The CCR-I results

\begin{tabular}{lcc}
\hline Rank & DMU & Score \\
\hline 1 & PSA & 1 \\
1 & ICTSI & 1 \\
1 & HPH & 1 \\
4 & APMT & 0.906 \\
5 & Eurogate & 0.696 \\
6 & OOCL & 0.612 \\
7 & K Line & 0.293 \\
\hline
\end{tabular}

Our results show that three DMUs obtained the score of 1 while the scores of other DMUs are $0.906,0.606,0.612$ and 0.293 , respectively. The results indicate that three DMUs are efficient container terminal operators and four DMUs are inefficient container 
terminal operators. Figure 2 shows the graphical display of the CCR-I results. The results show that HPH, ICTSI and PSA are efficient container terminal operators.

Figure 2 DEA results (single input and two outputs) (see online version for colours)

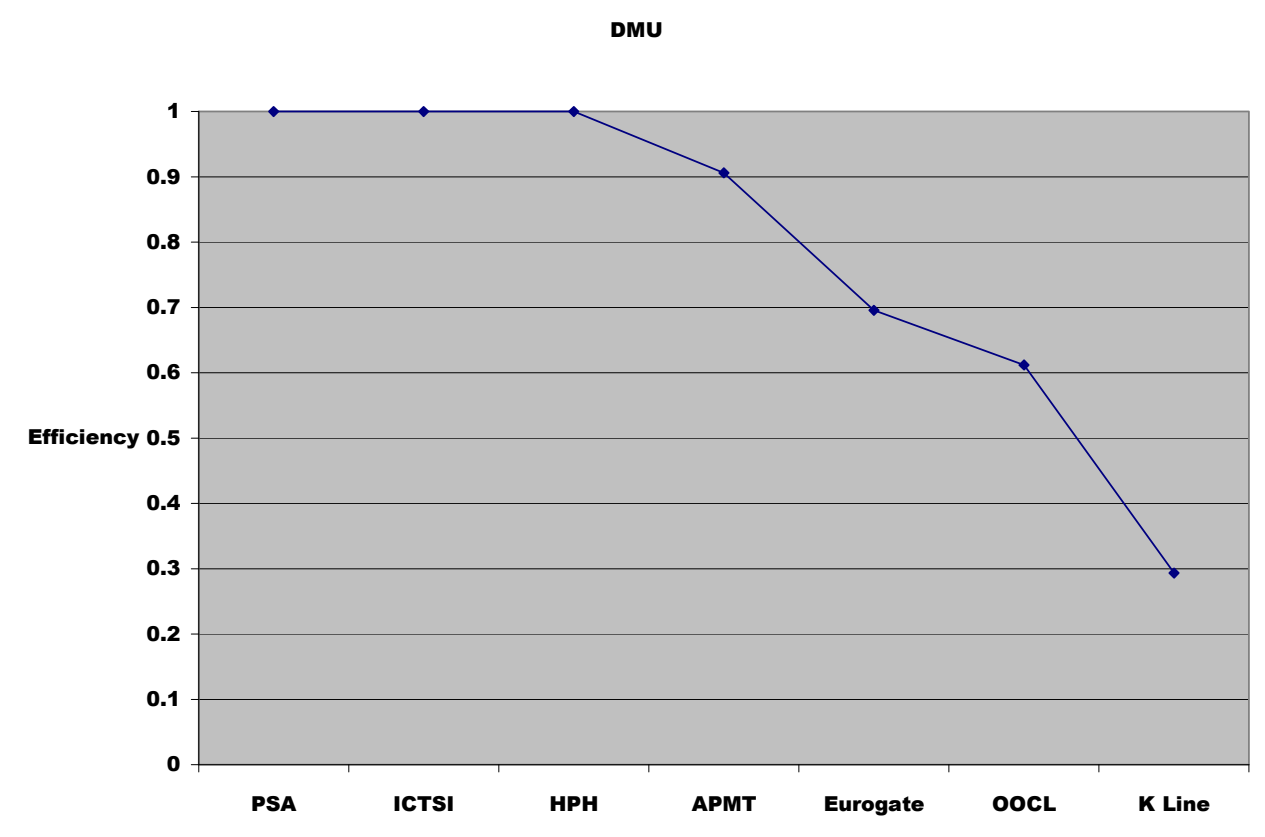

\section{Discussions and conclusions}

This study examines the relationships among the variables of operating cost, terminal throughput and profit of global container terminal operators. Our findings indicate that both terminal throughput and terminal profit are positively associated with operating cost. In order to provide a useful reference for a container terminal operator to determine the appropriate level of resource allocated to a container terminal and to guide the decision to terminal operations, this study develops two regression equations by using empirical data to estimate the level of outputs. The first regression equation (E1) $T T=-4.627+0.027 O C$ indicates that the expected terminal throughput is 0.027 of the operating cost beyond the constant level of 4.627 million TEUs. The second regression equation (E2) $T P=-203.422+0.551 O C$ indicates that the expected terminal profit is 0.551 of the operating cost beyond the constant level of 203.522 million (in USD). These two equations provide a reference guiding terminal managers to make a decision in adjusting the input level in the container terminal operations.

In this study, three DMUs including HPH, PSA and ICTSI receive the efficiency score of 1 . The results indicate that these terminals are operated efficiently. The terminal throughputs of these three DMUs are 62.00, 51.29 and 2.30 million TEUs, respectively. The results indicate that volume of throughput is not a key determinant of container terminal operator performance. Small terminal operators, such as ICTSI, can operate efficiently. On the other hand, our results suggest that all three efficiency DMUs are 
global stevedore container terminal operators. The findings suggest that the efficiency level of global stevedores' terminal operations is high when comparing with the efficiency level of global carriers' terminal operations. Accordingly, we propose a 'PROFIT' framework as an analytical framework for the operation and development of efficient container terminal operators. This 'PROFIT' framework consists of the following elements:

- Productivity: Productivity measures of output from production processes per unit of input. Efficient container terminal operations have high level of terminal throughput with the same level of input.

- Regional coverage: Enhancing the coverage of container terminal operations in a region can be a strategy for terminal operators to gain market power and serve markets more effectively.

- Operating efficiency: Efficient container terminal operations aim to minimise the input while satisfying the output levels to achieve high operating efficiency.

- Focus of business: To operate efficiently, the primary business focus of the global container terminal operators should be terminal operation instead of container shipping. These terminals are run as profit centres instead of cost centres.

- Internationalisation: The container terminal operators that have rich experience and expertise in managing container terminals are in a good position to extend their container terminal operation internationally.

- Terminal network: Faced with mergers and alliances among shipping lines and requirements for larger investment in terminal facilities, container terminal operators develop an extensive network to spread investment risk.

The implications of this study are two-fold, which can be drawn from the perspectives of both researchers and managers. From the research perspective, our DEA model identifies that the efficient global container terminal operators are global stevedore container terminal operators. The 'PROFIT' framework can serve as an analytical framework with essential elements to be taken into account by terminal operators. From a management perspective, this study provides two equations [i.e., equation (E1) to estimate the terminal throughput and equation (E2) to estimate the terminal profit] to predict the outputs of container terminal operations. It advances knowledge for terminal managers to understand the relationship between input and outputs and facilitate them to make effective business decisions.

A limitation of this study is that the data collected were based on secondary sources, of which we have no control over the accuracy and reliability of the data. Moreover, this study was limited to container terminal operations. For future research, the study can be extended to the other operations such as bulk terminals. A comparison between the container operations and the bulk cargo operations will be useful in understanding the terminal operations. 


\section{Acknowledgements}

This research was supported in part by Logistics Research Centre, The Hong Kong Polytechnic University.

\section{References}

Barber, E. (2008) 'How to measure the value in value chains', International Journal of Physical Distribution and Logistics Management, Vol. 38, No. 9, pp.685-698.

Bichou, K., Lai, K.H., Lun, Y.H.V. and Cheng, T.C.E. (2007) 'A quality management framework for the liner shipping companies to implement the 24-hour advance vessel manifest rule', Transportation Journal, Vol. 46, No. 1, pp.5-21.

Boussofiane, A., Dyson, R.G. and Thanassoulis, E. (1991) 'Applied data envelopment analysis', European Journal of Operational Research, Vol. 52, pp.1-15.

Carbone, V. and Martino, M. (2003) 'The changing role of ports in supply chain management: an empirical analysis', Maritime Policy Management, Vol. 30, No. 4, pp.305-320.

Cariou, P. (2008) 'Liner shipping strategies: an overview', International Journal of Ocean System Management, Vol. 1, No. 1, pp.2-13.

Charnes, A. Cooper, W.W. and Rhodes, E. (1978) 'Measuring the efficiency of decision making units', European Journal of Operational Research, Vol. 2, pp.429-444.

Cho, J.J., Ozment, J. and Sink, H. (2008) 'Logistics capability, logistics outsourcing and firm performance in an e-commerce market', International Journal of Physical Distribution and Logistics Management, Vol. 38, No. 5, pp.336-359.

Choi, H.R., Kim, H.S. and Park, J.B. (2003) 'An ERP approach for container terminal operating system', Maritime Policy Management, Vol. 30, pp.197-210.

Cooper, W.W., Seiford, L.M. and Tone, K. (2007) Data Envelopment Analysis, Springer, New York.

Drewry (2005) Annual Review of Global Container Terminal Operator, Drewry Shipping Consultants Limited, London, UK.

Drewry (2007) Annual Review of Global Container Terminal Operators, Drewry Shipping Consultants Limited, London, UK.

Geraldo, J., Beresford, A. and Pettit, S. (2003) 'Liner shipping companies and terminal operators: internationalization or globalization?', Maritime Economics and Logistics, Vol. 5, pp.393-412.

Heaver, D.T., Meersman, H. and Voorde, E.D. (2001) 'Co-operation and competition in international container transport: strategies for ports', Maritime Economics and Logistics, Vol. 8, No. 1, pp.82-99.

Heaver, D.T., Meersman, H., Moglia, F. and Voorde, E.D. (2000) 'Do mergers and alliances influence European shipping and port competition?', Maritime Policy and Management, Vol. 27, pp.363-373.

Lun, Y.H.V. and Browne, M. (2009) 'Fleet mix in container shipping operations', International Journal of Shipping and Transport Logistics, Vol. 1, No. 2, pp.103-118.

Lun, Y.H.V. and Quaddus, M.A. (2009) 'An empirical model for the bulk shipping market', International Journal of Shipping and Transport Logistics, Vol. 1, No. 1, pp.37-54.

Lun, Y.H.V., Lai, K.H. and Cheng, T.C.E. (2006) Shipping and Transport Logistics, McGraw Hill, Singapore.

Lun, Y.H.V., Lai, K.H. and Cheng, T.C.E. (2009) 'Intermodal transport capability', Shipping and Transport Logistics Book Series, Vol. 1, pp.17-33. 
Lun, Y.H.V., Wong, W.Y.C., Lai, K.H. and Cheng, T.C.E. (2008) 'Institutional perspective on the adoption of technology for the security enhancement of container transport', Transport Reviews, Vol. 28, No. 1, pp.21-33.

Martin, J. and Thomas, B. (2001) 'The container community', Maritime Policy and Management, Vol. 28, No. 3, pp.279-292.

Midoro, R., Musso, E. and Parola, F. (2005) 'Maritime liner shipping and the stevedoring industry: market structure and competitive strategies', Maritime Policy and Management, Vol. 32, No. 2, pp.89-106.

Notteboom, T. (2004) 'Container shipping and ports: an overview', Reviews of Network Economics, Vol. 32, No. 2, pp.86-106.

Notteboom, T. and Winkelmans, W. (2001) 'Structural changes in logistics: how do ports authorities face the challenges?', Maritime Policy and Management, Vol. 28, pp.71-89.

Robinson, R. (2002) 'Ports are elements in value-driven chain systems: the new paradigm', Maritime Policy and Management, Vol. 29, No. 3, pp.241-255.

Vis, I. and Koster, R. (2003) 'Transshipment of containers at a container terminal: an overview', European Journal of Operational Research, Vol. 147, pp.1-16.

Zhou, G., Min, H., Xu, C. and Cao, Z. (2008) 'Evaluating the comparative efficiency of Chinese third-party logistics providers using data envelopment analysis', International Journal of Physical and Logistics Management, Vol. 38, No. 4, pp.262-279. 